\title{
A classification framework for interactive digital artworks
}

\author{
Enrico Nardelli ${ }^{1}$ \\ Department of Mathematics \\ Univ. of Roma Tor Vergata, Roma, Italy \\ nardelli@mat.uniroma2. it
}

\begin{abstract}
We define Interactive Digital Artworks as Information Technology intensive systems for which spectators are involved in the production of the artistic output. We propose a novel framework for classification of interactive digital artworks built on the critical revision and refinement of previous work. Our approach is based on the input-process-output view of Information Systems. The classification framework is validated by applying it to the classification of 54 interactive digital artworks realized in Italy.
\end{abstract}

Key words: Digital art, Interactive content production, Classification framework

\section{Introduction and previous work}

By the term "Interactive Digital Artwork" (IDA, for short) we mean any artwork where digital technology is an essential component and which is interactive (in the common sense this word is used in IT). IDAs can be physical artworks placed in a public and open space (usually called "installations") or virtual artworks enjoyed on a personal device. Digital films/videos are usually not examples of IDA, nor is digital music, since they both lack the contribution of the user to the content production. But when the outcome of video animations or music pieces is modified according to user interaction they are examples of "interactive digital art".

In [6] it is suggested that any computer artwork should be considered as an information systems and six research themes are proposed. More specifically, the following three themes from [6] provide a context for our research:

- Computer Art as an Information Systems: each computer artwork can be abstracted by the input-process-output reference scheme tipically used for Information Systems.

- Computer Art and The Commercial Perspective: this is about management and economic issues. How to establish the value of an IDA? What about copyright? Which are the implications for IDA preservation for museum/gallery curators?

- Computer Art as a Socio-Technical Systems: Interactivity necessarily involves people in the system and in [6] it is written: "We should ask whether our current understanding of participation in systems development applies equally to the creation of computer artistic works".

Our research goal is to characterize and compare IDAs. To this aim we present a framework, or a scheme, that allows to arrange the various examples of IDAs in homogenous 
classes or categories. Using this classification framework/scheme, in the following simply classification, it will therefore be easier to discussing and/or producing and/or buying interactive digital art.

In this respect our classification is similar to the ones used in the standard fine arts regarding, e.g., painting techniques (oil, watercolours, fresco, pastel, gouache, ...), materials (paper, wood, metal, stone, canvas, silk, ...), tools (brush, pencil, roller, chalk, ...), which makes it easier to discuss and to teach about artworks.

We based the structure of our classification framework on the review of relevant literature concerning this theme $[8,4,3,9]$. Then our classification is validated by considering (a subset of) the artworks discussed in the IDA literature and showing that they can be grouped according to our classification in a meaningful way.

The novelty of our proposal with respect to previous work is that it is explicitly based on the standard input-process-output view used for discussing Information Systems.

Previous work addressing our research goal was published in 1999 by Sommerer and Mignonneau [8], in 2002 by Hannington and Reed [4], in 2004 by Edmonds, Turner, and Candy [3], and in 2008 by Trifonova, Jaccheri, and Bergaust [9]. The main emphasis in all these classifications was on the user interaction. Hence all proposals were centered around the various kinds of interactions and did not consider the more general viewpoint of IDAs as Information Systems.

The older classification in the literature is the one discussed in [8], addressing "interactive artworks". Since it is not focusing on the use of information technology it is not able to characterize its specific aspects.

Then, the classification in [4] is covering "interaction in multimedia applications", hence it considers a larger and different set of works, since many multimedia applications have no artistic component.

Subsequently, the classification in [3] discusses "relationship between the artwork, artist, viewer and environment", hence it does not cover those internal aspects of the artwork that are related to the processing of input from the artwork audience, which is a very important aspect of an IDA.

Finally, the classification proposed in [9] addresses "interactive installation art": on the one side it hence considers a narrower set of works (just the installations and not the artworks experienced on personal devices, which are more and more important means for user interaction in the Future Internet), but on the other side it has been built by focusing just on interactivity as the main aspect of IDAs.

In the rest of the paper we first present our classification (Section 2), then compare it to previous ones (Section 3), and finally discuss its validation (Section 4).

\section{The classification framework}

An information system is conventionally seen as a system which processes a given input to produce a desired output. We consider an IDA in the same way, as a system 
which receives a certain input, called content in this context, and producing as a result the output intended by the IDA author (i.e., the artist). It is also helpful to consider the process producing the intended output as if it were a function in a mathematical sense, that is an abstract "device" which at each time instant transforms its inputs into its outputs according to its mathematical specification.

The dimensions of the classification are:

content provider: who produces the raw material processed by the IDA, processing dynamics: which kind of variability has the processing itself, processing contributors: which are the sources affecting the dynamics of processing.

For each dimension we now provide different values, that are the labels of our classification. We use the term artist to denote the person or team who has invented and realized the IDA, audience to denote the human beings actively and consciously providing any kind of input to the IDA, and environment to denote any passive or not-conscious entity present in the environment surrounding the IDA.

Regarding the content provider dimension, the source providing the content to the IDA can be either the artist or the audience or the environment. This dimension has therefore 3 possible values, or points, and an artwork can be labeled, with respect to this dimension, with one, two or all the values.

Regarding the processing dynamics dimension, the processing function of an artwork can be static with the passing of time, or it can be dynamic, that is changing as time passes. Note that the change considered here is the intrinsic change of the processing function, not a change in its input parameters. But the input parameters may determine, partly or wholly, such a change. In the case of a dynamic processing function, we consider three values, in mutual exclusion, to be used for a better characterization of the artwork:

- predefined change, where changes to the function follows the plan defined by the artist;

- casual change, where changes to the function derive by random choices, even in the case the set or the domain of the possible choices have been completely pre-defined by the artists;

- evolutionary change, where changes follow an unpredictable path defined by the evolution (in a biological sense) of the processing function itself.

The single value for the static case plus the three above values for the dynamic one give a total of 4 values (points) for this dimension. An artwork can be labeled with exactly one of these values.

Regarding the processing contributors dimension, the elements driving the content processing can be self-contained in the IDA (hence, what the artist has put directly inside the artwork affects the processing), or these elements can arrive at the IDA through the interaction with the context the IDA is placed within (that is, the processing function has additional input parameters causing modifications to how the content is processed). 
In the latter case, the providers of values changing the behavior of the processing function can be the audience or the environment. The dimension has therefore 3 values (points) and an artwork can receive one, two or all the labels.

Note that, in strictly mathematical terms, inputs to a functions are all equals, hence the distinction between "content provider" and "processing contributors" dimensions has no compelling mathematical reason. But from the artist viewpoint this differentiation is an important one, since it distinguishes between what she has directly inserted in the artwork and what arrives from the outside of the IDA, both in terms of the raw material and its processing function.

Also, an artwork labeled both under "content provider" exclusively with artist and under "processing contributors" exclusively with artist is not an IDA, since it has no elements of interaction at all. But as long as, in at least one of these two dimensions, the artwork is labeled with at least one more label, then it is an IDA.

The overall classification space is therefore made up by $3 \cdot 4 \cdot 3$ values or points. Each one of them can also be thought as a "labeled cell" containing all IDAs that can be classified with the labels corresponding to the point itself. Note that an IDA can be classified at the same time under more than one cell.

To give an example, let us consider an IDA taking pictures of its audience (say, one every five minutes) and displaying them while dynamically modifying them on the basis of data provided by the environment where the work is placed, so that each displayed picture is casually altered by one of the many processing filters defined by the artist, where the parameters guiding the filter are based on values read second by second in the environment. Then the classification label for such an IDA is: [content provider:audience, processing dynamics:casual change, processing contributors:environment].

A real IDA similar to this one is described in [7]: an installation which is inspired by Andy Warhol's statement that "In the future everybody will be world famous for fifteen minutes" as well as by the pop-art style of his works. The visible part of the installation consists of a digital camera and a flat-panel monitor dressed up like a precious painting (see figure 1 left). A computer behind the scene runs a software that detects human faces in visitors' images taken by the camera, graphically transforms them, and then displays them for fifteen seconds. The graphical transformation actually applied is randomly selected among the ones pre-defined by the artist. In such a case the classification label would differ for the dimension processing contributors, whose value would be: artist, since the kind of processing executed on the content of the IDA depends only on what artist has directly provided within the artwork itself.

Another real IDA similar to the above two ones is described in [5]: an installation where the self-image of the spectator is changed by randomly chosen pre-defined functions whose specific input parameters are provided by the spectator itself. In such a case the classification label is: [content provider:audience, processing dynamics:casual change, processing contributors:audience]. 

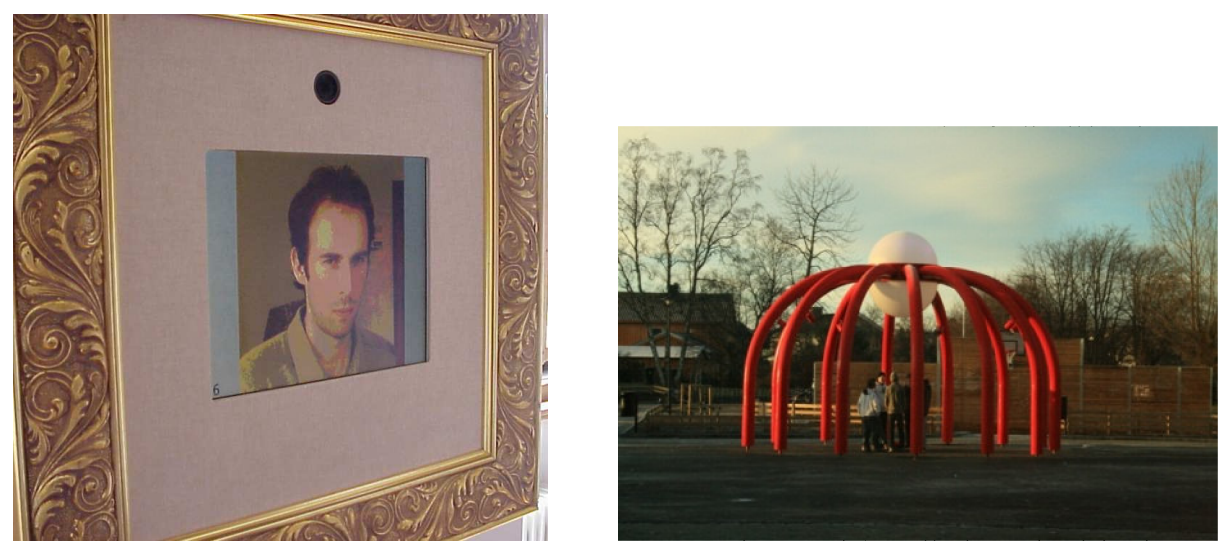

Fig. 1. The installations 15 seconds of fame (left), and Sonic Onyx (right).

Another real IDA is described in [1]: an installation receiving texts, images and sound files from its audience through their Bluetooth enabled handheld devices and converting them into sound compositions played through the seven loudspeakers located in seven arms of the sculpture (see figure 1 right). 3D sound effects are thus obtained in the space defined by the sculpture itself. The globe of the sculpture contains a lighting system changing light colors according to the different sounds it plays. The classification label for such an IDA is [content provider:audience, processing dynamics:static, processing contributors:artist].

Our classification overcomes the limitations of previously presented ones and explicitly targets IDAs by means of an approach that it is rooted on the standard input-processoutput view used for discussing Information Systems. Hence our proposal considers interactivity just as one of the components of the classification and is therefore more balanced.

We have not considered in our classification scheme issues related to hardware and software, either in terms of IDA development environment or in terms of the environment where the work is viewed, since both these issues are too much dependent on the current state of development of technology. Hence the characterization of these aspects, while useful from an historical point of view, does not make much sense for the intended use of IDA classification.

The classification might anyhow be refined by taking into account also the sensory channels by means of which interaction between IDA and its users happens, but this will be subject of further work.

\section{Comparison with previous frameworks}

In this section we provide a comparison between our classification framework and the previous ones. The comparison is not easy, since previous classification frameworks 
were based on the various kinds of interaction, while we have taken the more general approach of the Information Systems view.

To make the reader able to better understand the comparison we first recall here below the definition of previous classes provided by the previous works in the literature.

Sommerer and Mignonneau [8] discuss two types of interaction:

Pre-Designed: the viewer can choose her path of interaction among a set of limited and pre-defined possibilities,

Evolutionary: the artwork's processes are linked to interaction and interaction is evolving continuously.

Hannington and Reed [4] distinguish three types of interaction:

Passive: the content has a linear presentation and the user interacts by only starting and stopping the presentation,

Interactive: the user is allowed to choose her personal path through the content,

Adaptive: the user is able to enter her own content and control how it is used.

Edmonds, Turner, and Candy [3] discuss four categories of "relationship between the artwork, artist, viewer and environment":

Static: there is no interaction,

Dynamic-Passive: the artwork response is triggered by environmental factors,

Dynamic-Interactive: the human presence and/or actions (purposeful or not) are used as parameters for changing the artwork, whose processing rules are static,

Dynamic-Interactive (varying): the processing rules used by artwork to change its output are modified by an agent (the artwork software or a human).

Trifonova, Jaccheri, and Bergaust [9] consider three categories, with various subdivisions:

Interaction Rules: whether the rules controlling the interaction are static (i.e., they never change during artwork's life) or dynamic (i.e., they may change),

Triggering Parameters: whether the interaction rules depend just on the human presence, or it is required some form of human action, or it is the environment that controls them,

Content Origin: whether what the artwork shows is predefined by the artist, or provided by the user, or generated by the software, possibly through some evolutionary algorithm.

The relation between previous classifications and ours is represented in table 1, where an X means that what was classified under the others' class labeling the row can be classified with our class labeling the column. An O means that the others' class labeling the row has some relevance to our class labeling the column. 


\begin{tabular}{|c|c|c|c|c|c|c|c|c|c|c|c|}
\hline & \multicolumn{3}{|c|}{ Content Provider } & \multicolumn{4}{|c|}{ Processing Dynamics } & \multicolumn{3}{|c|}{$\begin{array}{l}\text { Processing Con- } \\
\text { tributors }\end{array}$} \\
\hline & & 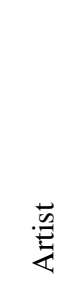 & 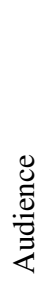 & 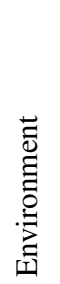 & 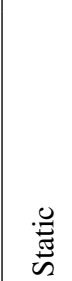 & 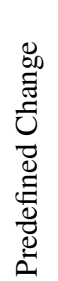 & 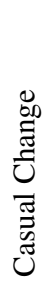 & 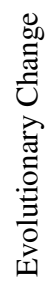 & $\begin{array}{l}\frac{\omega}{D} \\
\mathscr{n}\end{array}$ & $\begin{array}{l}\mathscr{U} \\
\stackrel{0}{0} \\
\stackrel{0}{Z} \\
\end{array}$ & 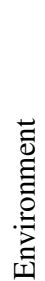 \\
\hline \multirow{2}{*}{ [8] } & Pre-designed & $x$ & 0 & & $x$ & $\mathrm{O}$ & & & $\mathrm{O}$ & $x$ & \\
\hline & Evolutionary & $\mathrm{X}$ & $X$ & & $\mathrm{O}$ & $\mathrm{X}$ & $X$ & $x$ & & $x$ & $\mathrm{O}$ \\
\hline \multirow{3}{*}{ [4] } & Passive & $\mathrm{X}$ & & & $\mathrm{X}$ & & $\mathrm{O}$ & & $\mathrm{X}$ & $\mathrm{O}$ & \\
\hline & Interactive & $X$ & 0 & & $X$ & & $\mathrm{O}$ & & & $X$ & \\
\hline & Adaptive & & $x$ & & & $X$ & $\mathrm{O}$ & & & $x$ & \\
\hline \multirow{4}{*}{ [3] } & Static & $\mathrm{X}$ & & & $\mathrm{X}$ & & & & $\mathrm{X}$ & & \\
\hline & Dynamic-passive & & & $X$ & $x$ & $\mathrm{O}$ & & & & & $\mathrm{X}$ \\
\hline & Dynamic-interactive & & $x$ & & $x$ & $x$ & & & & $\mathrm{X}$ & $x$ \\
\hline & $\begin{array}{l}\text { Dynamic-interactive } \\
\text { (varying) }\end{array}$ & & $\mathrm{X}$ & $\mathrm{X}$ & $X$ & $\mathrm{X}$ & $\mathrm{X}$ & & & $\mathrm{X}$ & $x$ \\
\hline \multirow{6}{*}{ [9] } & $\begin{array}{l}\text { Int.Rules: } \quad \text { Static } \\
\text { Int.Rules: Dynamic }\end{array}$ & & & & $X$ & $\mathrm{X}$ & $X$ & $x$ & $\mathrm{O}$ & $\mathrm{O}$ & \\
\hline & Tr.Par: Human Presence & & $\mathrm{O}$ & & & & & & $\mathrm{O}$ & $\mathrm{X}$ & \\
\hline & $\begin{array}{lr}\text { Tr.Par: } & \text { Human Action } \\
\text { Tr.Par: } & \text { Environment }\end{array}$ & & $\mathrm{O}$ & $\mathrm{O}$ & & & & & $\begin{array}{l}\mathrm{O} \\
\mathrm{O}\end{array}$ & $x$ & $x$ \\
\hline & $\begin{array}{r}\text { Cont.Orig: Predefined by } \\
\text { the Artist }\end{array}$ & $X$ & & & $\mathrm{O}$ & $\mathrm{O}$ & $\mathrm{O}$ & & $X$ & & \\
\hline & Cont.Orig: Users Input & & $\mathrm{X}$ & & $\mathrm{O}$ & & & & & $\mathrm{X}$ & \\
\hline & $\begin{array}{l}\text { Cont.Orig: Generated } \\
\text { / Algorithmic }\end{array}$ & $\mathrm{O}$ & & & & $\mathrm{O}$ & $\mathrm{O}$ & $x$ & $X$ & & \\
\hline
\end{tabular}

Table 1. Comparison with the previous classifications.

\section{Validation of the proposed framework}

In this section we discuss how the IDAs analysed in [2] can be classified on the basis of the proposed framework.

In [2] a complete analysis of interactive art installations in Italy is provided, focusing on technological tools used by artist in the field. The analysis focused on the 54 installations for which there was enough available information, and they were classified according to the framework of [9]. Many of them received the same classification, hence we considered for our validation only one instance of each class identified during this classification process.

It is interesting to note that in [2] it is explicitly recognized a weakness of the framework of [9], since it is reported that all the 54 installations were classified as static under the dimension "interaction rules" of the framework of [9]. This means that such a dimension was useless to classify the installations since its values were not able to differentiate among installations. 
We report in table 2 the most important descriptive data of one installation for each of the classes we have identified according to our framework. The number in the first column is the number by which installations are referred to in [2]. When the cell for the column "Physical Interface for direct manipulation by the user" is empty it means that the audience has no direct means for interacting with the IDA. Under the columns "Input Device(s)" and "Output Device(s)" we list the actual devices used by the IDA to, respectively, obtain data from the Audience or Environment and to produce data towards them. In the table 3 we show how the installations listed in table 2 are classified according to our framework. When more than one value appears under some dimension this means the IDA has received more than one label. The value PD/CC change is used to represent both the labels pre-defined change and casual change, since [2] does not distinguish between them. As you can see, our classification does not have the above cited weakness of the classification defined in [9], since in all dimensions more than one value is used. We use all the labels, but for evolutionary in the dimension "Processing Dynamics". This was expected, since this kind of processing dynamics is

\begin{tabular}{|c|c|c|c|c|c|}
\hline \# & Installation Name & Author & $\begin{array}{l}\text { Physical Interface for } \\
\text { direct manipulation } \\
\text { by the user }\end{array}$ & Input device(s) & Output device(s) \\
\hline 2 & $\begin{array}{l}\text { BMW Think } \\
\text { Like No One }\end{array}$ & $\begin{array}{l}\text { Studio } \\
\text { DotDotDot }\end{array}$ & Mobile Phones & $\begin{array}{l}\text { Camera, } \\
\text { Mobil Phones }\end{array}$ & Videoprojector \\
\hline 8 & FLAT/TRIX & Leonardo Betti & Table and objects & Camera & Lights, Speakers \\
\hline 9 & $\begin{array}{l}\text { Genova del } \\
\text { Saper Fare }\end{array}$ & $\begin{array}{l}\text { Studio } \\
\text { EnneZeroTre }\end{array}$ & Torch & Camera & Videoprojectors \\
\hline 10 & H:AND/RAYLS & Leonardo Betti & & Camera & Videoprojector \\
\hline 13 & If Shines & Leonardo Betti & Pipe & Microphone & $\begin{array}{l}\text { Videoprojector, } \\
\text { Speakers }\end{array}$ \\
\hline 14 & $\begin{array}{l}\text { Inconsapevoli } \\
\text { Macchine Poetiche }\end{array}$ & Giacomo Verde & Keyboard and mouse & Keyboard & $\begin{array}{l}\text { Computer display, } \\
\text { Speakers }\end{array}$ \\
\hline 15 & $\begin{array}{l}\text { Interactive } \\
\text { Collective Blu }\end{array}$ & $\begin{array}{l}\text { Maurizio } \\
\text { Bolognini }\end{array}$ & Mobile Phones & Mobile Phones & Videoprojector \\
\hline 16 & Interno Neve & Giacomo Verde & Tulle curtain & Motion Sensors & $\begin{array}{l}\text { Videoprojectors, } \\
\text { Speakers }\end{array}$ \\
\hline 19 & La cittá su misura & $\begin{array}{l}\text { Studio } \\
\text { EnneZeroTre }\end{array}$ & & Camera & Videoprojector \\
\hline 31 & Oracolo Ulisse & Studio Canali & Biomedical sensors & $\begin{array}{l}\text { Pressure Sensors, } \\
\text { Biomedical Sensors, } \\
\text { Accelerometer }\end{array}$ & $\begin{array}{l}\text { Videoprojector, } \\
\text { Speakers }\end{array}$ \\
\hline 41 & Sensual Zone & $\begin{array}{l}\text { Federico } \\
\text { Bucalossi }\end{array}$ & $\begin{array}{l}\text { Arcade Videogame } \\
\text { cabinet }\end{array}$ & Videogame controls & $\begin{array}{l}\text { Videogame display, } \\
\text { Headphones }\end{array}$ \\
\hline 42 & SmellLink & Ennio Bertrand & Keyboard, Mouse & Keyboard, Mouse & Laser Printer \\
\hline 45 & $\begin{array}{l}\text { The Art of } \\
\text { Italian Design }\end{array}$ & $\begin{array}{l}\text { Studio } \\
\text { EnneZeroTre }\end{array}$ & Torch & Camera & $\begin{array}{l}\text { Videoprojector, } \\
\text { Speakers }\end{array}$ \\
\hline 46 & thevirtualgallery.ors & $\begin{array}{l}\text { Maurizio } \\
\text { Bolognini }\end{array}$ & Keyboard, Mouse & Keyboard, Mouse & Videoprojector \\
\hline
\end{tabular}

Table 2. Installations considered for the validation of our classification 


\begin{tabular}{lllll}
$\#$ & Content Provider & Processing Dynamics & Processing Contributors & Other Installations \\
\hline \hline 8 & artist & static & artist & $21,22,23,24,28,43,44$ \\
\hline 10 & artist & static & audience & $\begin{array}{l}3,4,11,17,18,20,25, \\
26,35,36,39,40,47,48, \\
49,50,51,52,53,54\end{array}$ \\
\hline 41 artist & PD/CC change & artist & 6 \\
\hline 16 & artist & PD/CC change & audience & $\begin{array}{l}1,7,12,27,29,32,33, \\
34,38\end{array}$ \\
\hline 45 & artist & static & $\begin{array}{l}\text { artist } \\
\text { environment }\end{array}$ & \\
\hline 19 & artist & static & $\begin{array}{l}\text { audience } \\
\text { environment }\end{array}$ & \\
\hline 31 & artist & PD/CC change & artist & audience \\
\hline 42 & audience & static & artist & \\
\hline 46 & audience & PD/CC change & artist & 3,30 \\
\hline 15 & audience & PD/CC change & audience & \\
\hline 14 & $\begin{array}{l}\text { artist } \\
\text { audience }\end{array}$ & static & artist & 37 \\
\hline 13 & $\begin{array}{l}\text { artist } \\
\text { audience }\end{array}$ & PD/CC change & artist & \\
\hline 2 & $\begin{array}{l}\text { artist } \\
\text { audience }\end{array}$ & PD/CC change & audience & \\
\hline 9 & $\begin{array}{l}\text { artist } \\
\text { environment }\end{array}$ & static & artist & \\
\hline
\end{tabular}

Table 3. Classification of the considered installations

very sophisticate in mathematical terms and also in [2] it is noted that no installations of this kind was found in Italy.

The last column lists the numbers of all other installations classified with the same set of labels. One class (the one in the second row) covers almost one half of all analyzed installations, and two other classes (first and fourth rows) cover about one third of them: this coarseness is shared with the classification in [9] and suggests it is of real practical importance to extend this work by distinguishing also among the various sensory channels by means of which interaction between IDA and its users happens. Moreover, a further empirical validation of our classification needs to be done by directly interviewing the artists and getting their direct feedback on the new classification. Finally, the issues recalled in Section 1 in the research theme Computer Art and the Commercial Perspective are worth further investigations.

\section{Conclusions}

In this paper we have presented and discussed a novel framework for classification of interactive digital artworks (i.e., artworks based on ICT and where the user is directly involved in the production of the artistic output and called, for short, IDAs). The need 
for such a classification derives from the needs of relating and comparing homogeneous IDAs, of having a common description framework for researching, discussing and teaching about IDAs, and of definining "how-to" procedures for IDAs production and management.

We have built our classification framework on the basis of a critical revision and refinement of previous work. Its novelty lies in its being directly based on the inputprocess-output view considered for discussing Information Systems. Hence it allows to overcome weaknesses and limitations of the previous proposed ones. Our classification framework is validated by applying it to a set of 54 real-life examples of IDAs in Italy.

Acknowledgments. We would like to thank Letizia Jaccheri for useful and interesting discussions during the development of the work here described. Comments from referees helped in improving the presentation.

\section{References}

1. Salah Uddin Ahmed, Letizia Jaccheri, and Samir M'kadmi. Sonic onyx: Case study of an interactive artwork. In Fay Huang and Reen-Cheng Wang, editors, Revised Selected Papers of the 1st International Conference on Arts and Technology (ArtsIT'09), pages 40-47, YiLan, Taiwan, Sep 2009. Springer Verlag, Lecture Notes of the Institute for Computer Sciences, Social Informatics and Telecommunications Engineering (LNCSIST) vol.30. http:// www.springerlink.com/content/nx243t25h1448750/fulltext.pdf.

2. Leonora Cappellini. Interactive installation art in Italy: an analytical survey. Master Degree Thesis in Informatics for Humanities, Supervisors: Luciana Vassallo and Letizia Jaccheri, University of Pisa, 2009. http://www.idi.ntnu.no/ letizia/tesi_cappellini.pdf.

3. Ernest Edmonds, Greg Turner, and Linda Candy. Approaches to interactive art systems. In 2nd International Conference on Computer Graphics and Interactive Techniques in Australasia and South East Asia (GRAPHITE'04), Singapore, 113-117 2004. ACM.

4. Anne Hannington and Karl Reed. Towards a taxonomy for guiding multimedia application development. In 9th Asia-Pacific Software Engineering Conference (APSEC'02), Gold Coast, Queensland, Australia, December 2002.

5. Enrico Nardelli. A software based installation to assist self-reflection. In 11th Consciousness Reframed International Research Conference (CR-11), Trondheim, Norway, November 2010. TEKS - Trondheim Electronic Arts Centre.

6. Briony J. Oates. New frontiers for information systems research: Computer art as an information system. European Journal of Information Systems, 15:617-626, 2006.

7. Franc Solina, Peter Peer, Borut Batagelj, and Samo Juvan. 15 seconds of fame - an interactive computer-vision based art installation. In 7th International Conference on Control, Automation, Robotics and Vision (ICARCV'02), pages 198-204, Singapore, 2002.

8. Christa Sommerer and Laurent Mignonneau. Art as a living system: Interactive computer artworks. Leonardo, 32:165-173, 2001.

9. Anna Trifonova, Maria Letizia Jaccheri, and Kristin Bergaust. Software engineering issues in interactive installation art. International Journal of Arts and Technology, 1(1), 2008. 